\title{
O PERFIL DO PROFISSIONAL DOCENTE NO ENSINO SUPERIOR
}

\author{
THE PROFILE OF THE TEACHING PROFESSIONAL IN HIGHER EDUCATION
}

\author{
Rodi Narciso \\ Prefeitura Municipal de Sinop, Mato Grosso, Brasil. E-mail: rodynarciso1974@gmail.com
}

\section{Catyane Roberta Hauth}

Prefeitura Municipal de Sinop, Mato Grosso, Brasil. E-mail: catyhauth@gmail.com

DOI: https://doi.org/10.46550/amormundi.v2i5.118

Recebido em: 15.08.2021

Aceito em: 09.09.2021

\begin{abstract}
Resumo: $\mathrm{O}$ presente artigo é fruto de uma pesquisa bibliográfica acerca da temática do profissional docente no ensino superior, cujo objetivo é responder a questáo: Qual o perfil do profissional docente do Ensino Superior na atualidade? Isto posto, foram selecionadas como referências para este estudo artigos e livros oferecidos pela instituição e de acervo próprio das últimas décadas, que corroborassem com o tema em questáo. Foram explanadas as características do perfil deste profissional, no contexto do ensino superior, compreendendo as atribuições e desafios inerentes a profissão, bem como a sua atuação neste contexto específico, assim como as dificuldades encontradas por estes profissionais. Concluindo, com isso, que a qualidade de ensino no ambiente superior de ensino e, consequentemente, a valorização do docente são questôes indissociáveis, uma vez sendo este profissional o responsável pela formação de pesquisadores críticos, corresponsáveis na melhoria da sociedade da qual fazem parte. Todavia, essa modalidade de docência, apresenta barreiras a serem transpostas, dentre elas o próprio campo de formação deste profissional, condiçôes de trabalho, estrutura das universidades e, principalmente no seu currículo.
\end{abstract}

Palavras-chave: Professor. Formação. Perfil Profissional.

\begin{abstract}
This article is the result of a bibliographical research on the theme of professional teaching in higher education, whose objective is to answer the question: What is the profile of professional teaching in Higher Education today? That said, articles and books offered by the institution and from its own collection of the last decades, which corroborate the theme in question, were selected as references for this study. The characteristics of the profile of this professional were explained, in the context of higher education, including the tasks and challenges inherent to the profession, as well as their performance in this specific context, as well as the difficulties encountered by these professionals. Concluding, with this, that the quality of teaching in the higher education environment and, consequently, the valuation of the professor are inseparable issues, since this professional is responsible for the formation of critical researchers, co-responsible for improving the society of which they are a part. However, this type of teaching presents barriers to be overcome, including the field of training of this professional, working conditions, structure of universities and, mainly, in their curriculum.
\end{abstract}

Keywords: Teacher. Training. Professional Profile. 


\section{Introduçáo}

ema de muitas discussóes, a formação de professores, mais especificamente professores
de ensino superior, tem sido abordada constantemente urgindo elencar os saberes necessários para o exercício desta modalidade de docência.

Tendo em conta esta premissa, o objetivo em destaque deste artigo centra-se em responder à questão: Qual o perfil do profissional docente do Ensino Superior na atualidade? Para tanto, apresentar-se-á uma explanação acerca do perfil deste profissional, assim como as atribuiçóes e desafios inerentes a profissão, e as dificuldades encontradas por este na docência do Ensino Superior, tanto na perspectiva do professor em sala de aula, quanto a formação destes, uma vez que não possuem uma formação específica.

A escolha e delimitação do tema se deram a partir de experiências próprias enquanto acadêmica, no decorrer de discussóes sobre o tema nas aulas da especialização.

No que tange a formação de professores, Cunha (2013), discorre que para tanto é necessário se implantar a pesquisa neste processo de formação, haja vista que a mesma acompanha os movimentos ululantes do contexto sociocultural moldando o profissional docente, que seja na teoria, que seja na prática, de fato.

Este artigo será estruturado da seguinte forma. Num primeiro momento far-se-á uma explanação reflexiva sobre o perfil deste profissional, no contexto do ensino superior, compreendendo as atribuiçôes e desafios inerentes a profissão.

Num segundo tópico serão abordadas considerações acerca de atuação neste contexto específico, assim como as dificuldades encontradas por estes profissionais e o respaldo oferecido pelas próprias universidades para a qualificação deste profissional.

Concluindo, por fim, na apresentação da LDB no que tange a formação dos profissionais no Ensino Superior e a realidade encontrada por muitos profissionais ao exercer a profissão.

Portanto, este artigo não tem a intenção de esgotar o tema, mas sim, de levantar questôes e hipóteses a serem pensadas e, posteriormente, tomadas por objetos de estudos mais aprofundados.

\section{Perfil de atuaçáo do profissional docente do Ensino Superior}

A identidade do profissional docente nas universidades atualmente se pauta e se confunde com as mais variadas funçôes exercidas na Instituição de Ensino Superior e na sociedade.

Pereira e Anjos (2014) discorrem que as obrigações que delimitam a práxis docente deste profissional estão, na grande maioria das vezes, encobertas dentro do próprio fazer docente, haja vista deste possuir diversas formações de origem, das próprias afinidades tidas entre as diferentes áreas do saber, assim como das próprias discrepâncias existentes entre as IES - Instituiçôes de Ensino Superior.

As autoras (2014, p. 5) comentam ainda que é possível observar que os profissionais que atuam nesta área possuem uma didática oriunda de seus cursos de licenciatura, ou ainda de cursos de especialização.

Um aspecto bastante comum, principalmente no início da carreira do professor, é a reprodução do exercício da docência, ou seja, repetir métodos, utilização de recursos pedagógicos e características de outro professor, é a interpretação da 
visão da docência que se teve enquanto aluno

Neste caso, portanto, os professores recém diplomados na realidade aprenderam algo sobre como devem dar aulas, tendo conhecimentos de alguns recursos que lhes amparariam neste processo, dando a sensação sobre o que é ensinar e o que é aprender. Esses conhecimentos e vivências, na grande maioria das vezes, são os norteadores do processo de ensinagem que constituem.

Rhoden e Rhoden (2017, p. 34), razoam que,

[...] professor universitário não se forma hoje para atuar necessariamente numa universidade, mas sim num complexo sistema de Ensino Superior. Assim sendo, torna-se necessário que este professor se prepare permanentemente para agir nesse meio; surgem, então, novas necessidades formativas.

Corroborando com esse ponto de vista o fato de inexistir ou serem fragilizadas as formações específicas para o docente universitário desta área. Uma vez que a profissão docente se constitui também a partir da práxis real, no exercício da função.

Não obstante a LDB - Lei de Diretrizes e Bases da Educação Nacional de 9394/96 apresenta a necessidade de formação docente para o Ensino Superior, nas áreas Stricto Sensu, podendo ser mestrado e/ou doutorado (BRASIL, 1996), todavia, essas formaçóes focam na formação do professor pesquisador, e não da formação pedagógica propriamente dita. (BAZZO, 2006).

Segundo Miranda (2006, p.135)

[...] o professor pesquisador centra-se na consideração da prática, que passa a ser meio, fundamento e destinação dos saberes que suscita, desde que esses possam ser orientados e apropriados pela ação reflexiva do professor.

Assim sendo, cabe ao professor pesquisador o aperfeiçoamento de sua capacidade reflexiva. Alarcão (2010, p.43) explica que,

[...] a noção de professor-reflexivo baseia-se na consciência da capacidade de pensamento e reflexão que caracteriza o ser humano como criativo e não como mero reprodutor de ideias e práticas que lhe são exteriores. É central, nesta conceptualização, a noção de um profissional como uma pessoa que, nas situaçóes profissionais tantas vezes incertas e imprevistas, atua de forma inteligente e flexível, situada e reativa.

Portanto, ao se tornar professor/docente na esfera de ensino superior, são retomadas experiências que foram vividas enquanto aluno, oportunizando uma práxis que descreve o modelo que predomina no âmbito universitário, tendo em conta que não se podem descartar observaçôes relativas de seus alunos, bem como a capacidade acerca do aprendizado autodidata.

A chegada e construçáo da vida profissional no ensino superior envolve o ato de enfrentar novos desafios, partindo de uma nova perspectiva, tanto pessoal quanto profissional, se tornando diariamente mais complexas à medida que estes tomem consciência do que exige sua profissão, ou seja, especialidades específicas que urgem serem apreendidas.

Para grande parcela dos docentes do ensino superior, a entrada factual na carreira,

[...] ocorre normalmente de forma circunstancial para muitos dos professores, enquanto para um pequeno grupo é uma escolha pessoal, o que indica um forte componente de envolvimento afetivo com a docência desde um período anterior à sua opção profissional. Algumas das percepçóes marcantes deste 
período envolvem: a solidão pedagógica, a insegurança, frente aos alunos e à disciplina, tanto em termos de manejo de classe, quanto de domínio de conteúdo da disciplina; a centração no conteúdo específico e na necessidade de vencer o programa a qualquer custo; a inadequação para a docência, ou seja, a falta de domínio de uma pedagogia para este nível de ensino (ISAIA; BOLZAN, 2011, p. 190).

Presumia-se, num passado não tão longínquo, que para lecionar na esfera universitária fosse suficiente ter "bacharelado", pois para a época vigorava o ditado de "quem sabe, sabe ensinar", no entanto, este postulado não se confirmou, uma vez que o ensino superior exige domínio de conhecimentos técnicos específicos, de pesquisa e didática

Behrens (2011) afirma que cabe refletir:

[...] o professor profissional ou o profissional liberal professor das mais variadas áreas do conhecimento, ao optarem pela docência no ensino universitário, precisam ter consciência de que, ao adentrar a sala de aula, o seu papel essencial é o de ser professor". Para tanto, será preciso superar crenças baseadas nas premissas: o docente nasce feito; para ser docente basta ser um bom profissional em sua área; para ensinar basta saber o conteúdo (p.444)

Sendo assim, para ascender neste contexto, tendo os resultados almejados no ensino superior alcançados, faz-se necessário que o profissional produza/construa conhecimentos, atentando-se para à formação e desenvolvimento dos profissionais que atuam nesta esfera.

Isto posto, para o ato de ensinar, o docente do ensino superior necessita possuir práticas e conhecimentos que excedam sua área de conhecimento/especialidade e suas especificidades.

Segundo Libâneo (2004, p. 122), que reitera Davydov,

[...] a coisa mais importante na atividade científica não é a reflexão nem o pensamento, nem a tarefa, mas a esfera das necessidades e emoçóes. (...) As emoções são muito mais fundamentais que os pensamentos, elas são a base para todas as diferentes tarefas que um homem estabelece para si mesmo, incluindo as tarefas do pensar. (...) A função geral das emoções é capacitar uma pessoa a pôrse certas tarefas vitais, mas este é somente meio caminho andado. A coisa mais importante é que as emoçóes capacitam a pessoa a decidir, desde o início se, de fato, existem meios físicos, espirituais e morais necessários para que ela consiga atingir seu objetivo.

Destarte, a inevitabilidade de desenvolver açóes cujo foco, seja voltado para a formação continuada a fim de suprir demandas de deficiências entre muitos dos profissionais que atuam no contexto da Educaçáo Superior é pressuroso, particularmente devido muitos destes atuarem na formação específica de docentes para a Educação Básica. A partir do pressuposto de que devem se implantar novas propostas educativas e renovar o perfil dos futuros profissionais, tornase imperioso a formação de professores com vistas a reformulação de valores e didática, de modo a profissionalizar a ação docente e qualificar o processo educativo.

Por conseguinte, o perfil do profissional docente deve ser reconstruído baseado em situaçôes pertinentes à docência. Não há como obter status em uma profissão se não houver mudanças no âmbito didático-pedagógico. O profissional que se envolve e acredita na causa, reconhecendo suas necessidade e limitaçóes do seu alunado, deve ter seus saberes potencializados por intermédio da formação continuada e de forma permanente aprofundando assim suas pesquisas dentro da área de atuação. 
Somente com profissionais qualificados e compromissados em buscar respostas para essas situaçóes pontuadas, ter-se-á o tão famoso sucesso que se espera na formação dos futuros profissionais.

\section{A formaçáo do profissional de educação no Ensino Superior à luz da LDB}

Mesmo com diversas discussóes acerca da carência de formação continuada do corpo docente universitário, percebe-se que há ainda uma parcela - embora pequena, da comunidade e indivíduos que entendem as políticas públicas e percebem o quão é importante a prontidão pedagógica para o ensino superior como algo secundário.

Diferente de outros cursos, para exercer a docência no ensino superior não há curso específico regulamentado. A LDB 9394/96 no artigo 66 (BRASIL, 1996), reconhece que os profissionais de docência, estejam capacitados em cursos de pós-graduação, preferencialmente em cursos stricto sensu. As brechas da Lei nos proporcionam interpretaçóes ambíguas, e ainda dão livre arbítrio as IES, para que criem seus próprios regimentos e estatutos.

Essas deficiências nas políticas públicas quanto ao ensino superior, de acordo com Cunha (2013, p.45), oportunizam a legitimação do discurso das universidades quanto aos conhecimentos oriundos de seus próprio cursos de licenciatura para a práxis docente do E.S., "[...], através de seus cursos de licenciatura, afirma haver um conhecimento específico, próprio para o exercício da profissão docente e legitimado por ela na diplomação, nega a existência deste saber quando se trata de seus próprios professores".

Rios e outros (2016, p. 146, apud Pachane, 2005), comentam que,

[...] que essa situação de desprestígio à formação pedagógica do professor universitário ocorre não só no Brasil, mas também em outros países, como a Espanha e os Estados Unidos. O autor enfatizou a necessidade de que tal situação seja mudada e que se dê maior atenção a esse tema. Diante disso, é importante refletir sobre como reverter esse quadro para que haja valorização do ensino e da formação pedagógica na universidade.

Consoante nesta mesma linha, para Pimenta e Anastasiou (2002), arrazoam que a Lei não concebe o processo de formaçáo para a docência no ensino superior com todo o rigor que necessita. Saber dialogar com a realidade e os alunos, levá-los à construção consciente da ética, da cidadania, das relaçôes político-sociais e afetivas são fundamentais no exercício das atividades pedagógicas. Todas juntas em uma única aula, na qual, além de possibilitar o aprendizado sobre o rigor característico de cada ciência, o professor possa revelar por meio de suas açóes na sociedade um profissional competente e múltiplo nas várias relaçôes que necessita desenvolver durante sua atuação.

Atenta-se, porém, que a profissão de professor no ensino superior, ganha status quando o profissional é formado em áreas como engenharia, medicina, odontologia, direito entre outras de destaque. Isso demonstra de certa forma, uma valorizaçáo social do atributo de "professor universitário"; não obstante, de outro lado, uma valorização de sua competência enquanto profissional; isto significa que ser apenas professor, aparenta ser pouco e tem pouco reconhecimento. (VASCONCELOS, 1998).

Hodiernamente os cursos de extensão, se dividem nos níveis de lato sensu (especialização) e stricto sensu (mestrado e doutorado). O mérito de especialista é atribuído após cumprir uma 
carga horária de estudos que superam a 360 hs. Já, para mestre, exige-se que além das aulas, o acadêmico o participe em seminários como ouvinte e com apresentação de trabalhos, além da dissertação em face de uma banca examinadora. Para o título de doutor, há um aumento significativo de carga horária e seminários, seguidos da defesa da tese, diante de uma banca examinadora formada por doutores.

A fim de favorecer as IES, a contratação dos profissionais docentes, tem como prioridade a formação de mestre ou doutor, pois estes títulos é que impulsionam a avaliação dos cursos. Contudo, as chances de se ter profissionais que nunca encararam uma sala de aula é grande, mas também nesse quadro, pode-se ter mentes brilhantes, com muita base em sua formação.

As possíveis formaçóes recaem, no entanto, sobre os cursos que formam os professores, além dos oferecidos pelas próprias instituições, através de programas de capacitação. As IES, podem e devem ser local de troca de conhecimentos, bem como lugar de criação e geração de novas possibilidades de aprendizados, instigando os profissionais docentes a serem pesquisadores. Nessa etapa, a pesquisa deve ser voltada para a descoberta de como oferecer conhecimento de modo que os alunos possam aprender.

Compor o perfil de um profissional docente, não se faz apenas através de cursos e capacitaçóes, é imprescindível a prática, experiências, que são adquiridas através de trocas e reflexôes com os colegas de profissão, fato este que contribui muito para o desempenho enquanto docente.

Nos últimos anos, a prática docente no ensino superior, vem sendo questionada, e com razão, pois os professores, salvo exceçôes, vem deixando de lado algumas de suas características. Conquanto, como mencionado neste artigo, o profissional docente no ensino superior deve atentar-se à prática pedagógica e profissional, buscando a harmonia entre os saberes, para chegarmos ao proficiente, e tão indispensável, profissional docente de ensino superior.

\section{Conclusão}

Neste breve estudo procurou-se evidenciar reflexôes a respeito do exercício da Docência do Ensino Superior, o qual permite-nos afirmar o quão necessário é a criação e implementação de programas direcionados à formaçáo pedagógica do profissional, além de promover açóes que despertem o compromisso com o desempenho educacional.

Esta ação deve estar voltada, primeiramente a autoestima do profissional e seu alunado, para aí então, subsidiar a área pedagógica, com ênfase as novas metodologias de ensino e prática destas ações, levando em consideração os fatores internos e externos.

O trabalho voltado para a autoestima, restringe-se em manter o seu alunado consciente e disposto, ciente de sua capacidade em aprender, mesmo que, seu aprendizado ocorra no seu tempo específico e náo no tempo dos demais. Partindo desse pressuposto, cada peculiaridade, transparece a dedicação maior por parte do aluno x professor.

Os docentes dos últimos tempos se deparam com diversos desafios quanto a revolução tecnológica e sofrem diante das mudanças na sociedade contemporânea, decorrente da globalização e reformas neoliberais. Entre suas atribuições, se destaca a função em transformar cidadãos, em seres conscientes, críticos e capazes de adquirir, aprimorar e construir o seu conhecimento. E que os profissionais possam ser capazes de acreditar e estimular humano como fonte transformadora 
da realidade, através da pesquisa e a reflexão.

Cabe ao professor pesquisador a árdua tarefa de trazer a luz novos conhecimentos, oferecer desafios e sair da zona de conforto, buscando enfrentar os percalços que a educação impóe, construindo uma nova identidade de profissional universitário, com formação digna de ser considerado "Professor", fazendo com que essa formação o direcione, de modo a ser um profissional que visa humanização, justiça, presando pela ética e pela prática reflexiva que sua práxis merece.

A prática pedagógica deve trazer à tona, a proporção real do significado de docente, uma vez que adquirir e transmitir conhecimento é um ato nobre e merecedor de reconhecimento e valorização.

\section{Referências}

ALARCÃO, Isabel. Professores reflexivos em uma escola reflexiva. São Paulo: Cortez, 2010. (Coleção questóes de nossa época, v.8).

BAZZO, Vera Lúcia. Algumas reflexóes sobre a profissionalidade docente no contexto das políticas para a Educação Superior. In: RISTOFF, Dilvo; SEVEGNANI, Palmira (Org.). Docência na Educação Superior. Brasília: Instituto Nacional de Estudos e Pesquisas Educacionais Anísio Teixeira, 2006. (Coleção Educação Superior em Debate; v. 5)

BEHRENS, Marilda Aparecida. Docência universitária: formação ou improvisação? Revista Educaçáo, Santa Maria, v. 36, n. 3, p. 441-454, set./dez. 2011.

BRASIL. Lei no 9.394, de 20 de dezembro de 1996. Estabelece as diretrizes e bases da educação nacional. Disponível em: <http://www.planalto.gov.br/ccivil_03/Leis/L9394.htm>. Acesso em 05 de jan. de 2021.

CUNHA, Maria Isabel. O tema da formação de professores: trajetórias e tendências do campo na pesquisa e na ação. Educação e Pesquisa, São Leopoldo: Universidade do Vale do Rio dos Sinos, p.1-18. 2013

LIBÂNEO, José Carlos. Organização e Gestão da Escola: teoria e prática. Goiânia: Alternativa, 2004 .

MIRANDA, M. G. de. O professor pesquisador e sua pretensão de resolver a relação entre a teoria e a prática na Formação de Professores. In: ANDRÉ, M. O Papel da pesquisa na formação e na prática dos professores. 5 ed. Campinas: Papirus, 2006. (p.129-143)

PIMENTA, Selma Garrido; Anastasiou, Lea das Graças C. Docência no ensino superior. São Paulo: Cortez, 2002.

PIMENTA, Selma Garrido; Anastasiou, Lea das Graças C. Tessituras formativas: articulação entre movimentos da docência e da aprendizagem docente. In: ISAIA, S.; BOLZAN, D.P.V.; MACIEL, A.M.R. (Org.). Qualidade da educação superior: a universidade como lugar de formação. Porto Alegre: Ed. da PUCRS, 2011. p. 187-190.

RIOS, Gilma Maria; GHELLI, Kelma Gomes Mendonça; SILVEIRA, Ludiana Martins. Qualidades de um professor universitário: perfil e concepçóes de prática educativa. Ensino 
Em Re-Vista | Uberlândia, MG | v.23 | n.1 | p.135-154| jan./jun. 2016| ISSN 1983-1730. Disponível em:< http://www.seer.ufu.br/index.php/emrevista/article/view/35408. Acesso em 05 de fev. de 2021.

VASCONCELOS, Maria Lúcia M. Carvalho. Contribuindo para formação de professores universitários: relato de experiências. In: MASETTO, Marcos Tarciso (Org.). A Docência na universidade. Campinas: Papirus, 1998 (p. 77-93). 